\title{
Growing PEACHnet: Building a Practice-Based Research Network in Western Colorado
}

\author{
Andrea Nederveld, MD, MPH, Kelsey Fife Duarte, MPH, and \\ Elena T. Broaddus-Shea, PhD
}

Introduction: Practice-based research networks (PBRNs) have long sought to engage with communities and address questions relevant to multiple stakeholders and real-world primary care practice. Topicgenerating processes that involve these stakeholders are crucial for identifying these questions. PBRNs often focus on certain populations or geographic areas. We are forming a new PBRN to address the health concerns and research interests of people in communities in Western Colorado.

Methods: To engage with and determine the questions important to multiple stakeholders in communities in western Colorado, we conducted community meetings at which we used Photovoice followed by Nominal Group Technique in group discussions across the region. We then conducted a survey to develop a list of priority research topics.

Results: Multiple stakeholders were ready and eager to engage with us to form a PBRN. Across all communities, many of the topics that emerged were related to the social determinants of health.

Mental health-specifically, lack of access to services and high suicide incidence-was the most important topic according to community members. This was consistent across groups of stakeholders and corroborated other community work such as Community Health Needs Assessments.

Discussion: Using participatory methods increased our stakeholder engagement and helped build strong community-academic partnerships for our PBRN-related research. Use of Photovoice allowed all participants to express their thoughts and ideas and led to a clear path forward for this new research network. (J Am Board Fam Med 2022;35:115-123.)

Keywords: Colorado, Community-Based Participatory Research, Family Medicine, Nominal Group Technique, Photovoice, Practice-Based Research Network, Primary Health Care, Research Priority Identification,

Social Determinants of Health, Surveys and Questionnaires

\section{Background}

Practice-based research networks (PBRNs) are generally understood to be groups of practices or practicing clinicians interested in conducting real-world clinical research that will improve primary care

This article was externally peer reviewed.

Submitted 1 July 2021; revised 8 September 2021; accepted 13 September 2021.

From the University of Colorado School of Medicine Department of Family Medicine (AN, KFD, ETBS).

Funding: This project was funded through a PatientCentered Outcomes Research Institute ${ }^{\circledR}\left(\mathrm{PCORI}^{\circledR}\right)$ Eugene Washington PCORI Engagement Award (EA\#8203). The statements presented in this article are solely the responsibility of the authors and do not necessarily represent the views of the Patient-Centered Outcomes Research Institute ${ }^{\circledR}$ $\left(\mathrm{PCORI}^{\circledR}\right)$, its Board of Governors, or Methodology Committee.

Conflict of interest: None.

Corresponding author: Andrea Nederveld, MD, MPH, 12631 East 17th Avenue, Box F496, Aurora, CO 80045 (Email: andrea.nederveld@ cuanschutz.edu). practice. ${ }^{1}$ As such, PBRNs have a long history of conducting research that examines clinical processes and patient outcomes. ${ }^{2,3}$ Through PBRNs, investigators and practicing clinicians have partnered to discuss many important clinical questions, such as headache imaging and treatment, asthma care, and management of miscarriage in primary care, often using pragmatic and straightforward data collection methods. ${ }^{4}$

Colorado's strong track record of effective PRBN work began in 1978 with the Family Medicine Information System (FMIS), an early computerized system that focused on collecting and evaluating data from several practices related to practice administration, teaching, and analysis of diagnoses and patient populations. ${ }^{5}$ In 1981, researchers and clinicians from the United States and Canada, including several from Colorado involved in FMIS, founded the Ambulatory Sentinel Practice Network, ${ }^{6}$ 
Figure 1. Engagement timeline and process.
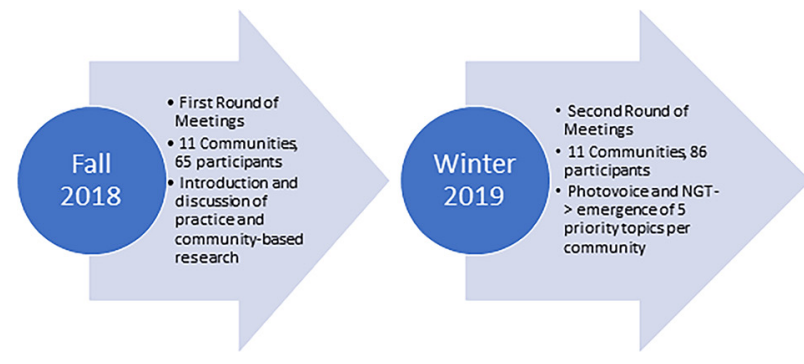

which established PBRNs as effective mechanisms to study clinical problems in primary care practice. ${ }^{3}$ Since then, PBRN infrastructure has continued to grow in Colorado, with the development of several smaller PBRNs under a statewide umbrella PBRN, called the State Network of Ambulatory Practices and Partners. ${ }^{7}$

Yet, until recently, most PBRN work in Colorado has taken place in the eastern half of the state, with little involvement of practices from the mountainous western slope. We believed a regional PBRN was needed because the culture of western Colorado is quite different from that of the Denver Metropolitan area and from the eastern plains, where there is an existing regional network. People in western Colorado tend to be more conservative politically and occasionally distrustful of outside influences.

Over time, there has been increasing interest in using community-based participatory research techniques in PBRNs. ${ }^{8}$ Many PBRNs include community members and patients on advisory boards or in other partnering capacities. ${ }^{9}$ In addition, expert recommendations to increase primary care and public health integration support the need for multi-stakeholder collaboration, including research networks. ${ }^{10}$ Embracing these ideas, we envisioned a network that included not only practices but also other stakeholders such as community-based organizations (CBOs), local public health departments, educational institutions, and community members. In 2018, we began an effort to develop a region-specific network in western Colorado. We chose the name Partners Engaged in Achieving Change in Health Network, or PEACHnet, as a nod to the agricultural industry in western Colorado and our multi-stakeholder approach. This article discusses the engagement methods we used to develop the network, highlights our use of Photovoice to elicit input on priority topics, and
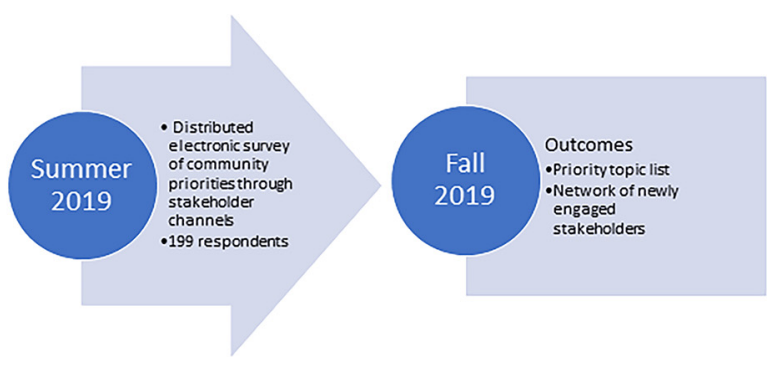

describes what we learned from multiple stakeholder groups.

\section{Methods}

We used the principles of community engagement outlined by Israel as a foundational guide to our approach. ${ }^{11,12}$ These principles include building on existing community strengths and resources, sharing power and developing equitable partnerships, fostering co-learning and capacity building, conducting research relevant to local public health issues, and addressing the multiple determinants of health. The project was reviewed by the Colorado Multiple Institutions Review Board and deemed exempt.

Our engagement work consisted of 2 rounds of stakeholder meetings followed by a survey conducted between the summer of 2018 and the fall of 2019 (see Figure 1). We identified potential stakeholders (primary care clinicians and staff, community members, public health workers, staff from community-based organizations) through multiple channels, initially working with a group of people known as Regional Health Connectors (RHCs). ${ }^{13}$ The Colorado RHC program began with the State Innovation $\mathrm{Model}^{14}$ project, funded by the Agency for Health care Research and Quality. This program was intended to accelerate health care transformation by improving quality, lowering costs, and improving outcomes through collaborative models. As part of this process, each Health Statistics Area in Colorado identified an RHC to facilitate connections and partnerships between health care providers, public health, and CBOs. As such, these individuals were able to provide us with connections to multiple stakeholders. We also worked with a regional health insurance provider and 2 independent practice associations to connect with health care providers across the region and leverage our own personal and professional connections. 
Figure 2. Communities where first round (stars) and second round (squares) meetings were held.

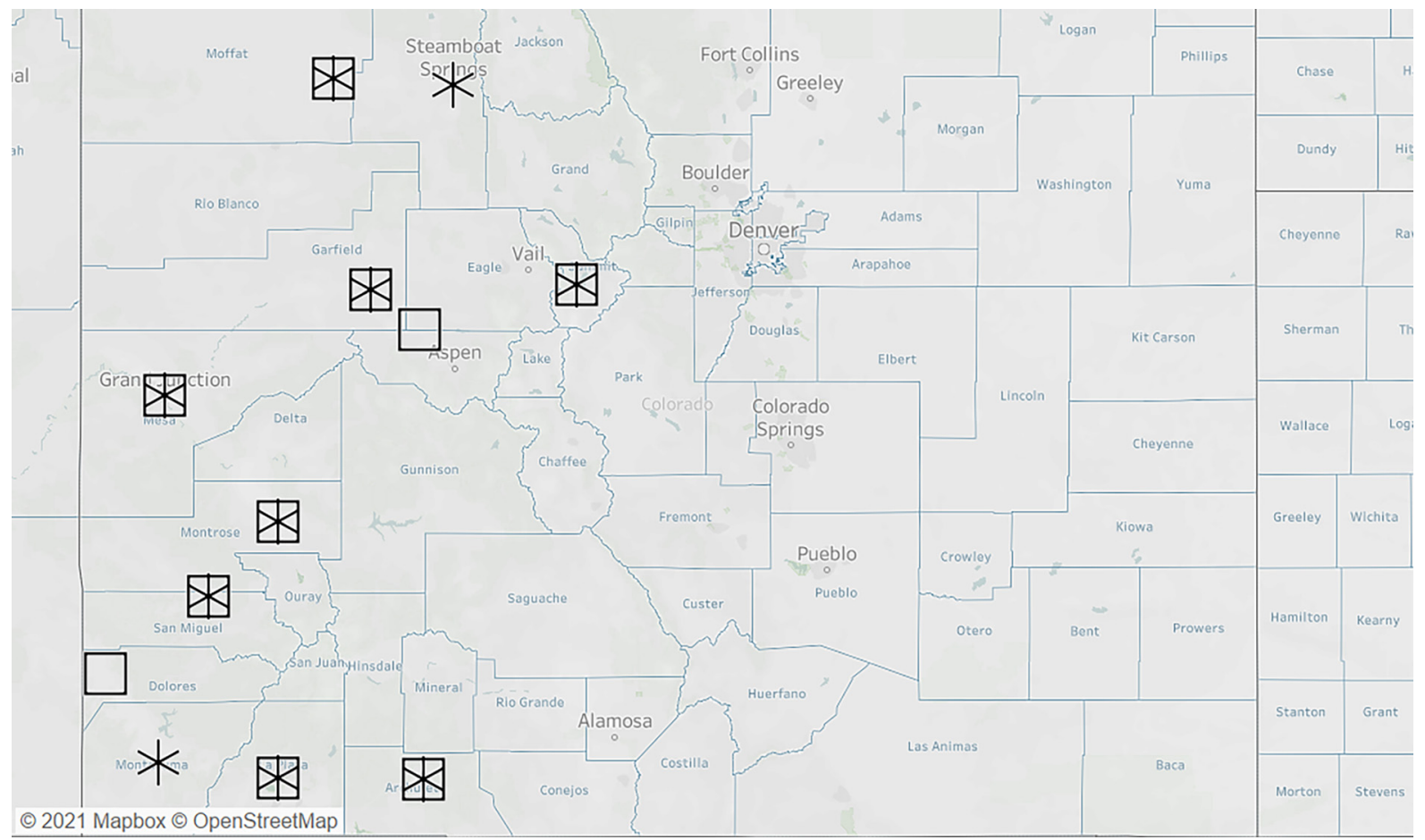

The purpose of the initial round of meetings was to meet people, introduce the idea of forming a regional research network, and discuss basic principles of community-engaged research. We recruited participants (identified via the channels described above) by first sending an email explaining our goal regarding network development and our plans for community meetings. We offered to connect individually with anyone who had questions. Once meeting times were set, we asked people to invite friends or coworkers who might be interested. We provided a meal at each meeting and gave each participant a $\$ 25$ gift card as a token of appreciation for their time and effort.

After making connections during the first round of meetings, we used the second round of meetings to identify topics and resulting research priorities important to diverse stakeholders in these communities. Recruitment for these meetings was conducted in the same way as the first round of meetings; all attendees from the first meetings were invited to attend second meetings and again were encouraged to invite friends or coworkers. We again provided meals and $\$ 25$ gift cards to participants.

As we were committed to a topic-generating process that allowed people to express their own perspectives and opinions on the direction our research should take, we selected 2 participatory methods, Photovoice, ${ }^{15,16}$ and Nominal Group Technique $^{1,7}$ to use in the second round of meetings. Although there are many useful participatory group discussion methods available, we believe these 2 methods would encourage all meeting attendees to share their perspectives and opinions. Photovoice is a research methodology that allows people to photographically document and narrate their own stories, essentially putting data collection in the hands of community members. ${ }^{15}$ Moreover, because it requires no special training or expertise, it encourages more equitable participation in knowledge creation and idea-sharing in situations where power levels differ among participants-for example, during discussions that include health professionals and community members. ${ }^{18}$ In emailed invitations, we explained that we were interested in determining which topics were most important to stakeholders and seemed ripe for research for our network to consider in work moving forward. We asked participants to take pictures of things that either promoted or detracted from health in their communities. We requested that each participant send us at least 2 of these images before the meeting to create a presentation to share everyone's 
images. At the meetings, we asked each participant to present their images and explain what the picture represented and how that topic promoted or detracted from health.

After the presentation and discussion of the shared images, we used Nominal Group Technique (NGT) to create a list of all topics elicited by the images. Nominal Group Technique was developed in the 1960 s as a method for facilitating prioritization and group decision-making. ${ }^{17}$ Briefly, it is a process that asks all participants first to provide input in a round-robin format. This is followed by discussion and categorization of ideas. We used this process to develop a list of topics that emerged from the shared images. When this list was complete, we conducted a dot-voting process to rank the relative importance of each topic not just as a health issue but also for future research. Each participant had 3 votes and could place them all on 1 topic or divide them between multiple topics.

Following the topic-generating and ranking activities of the second round of meetings, we compiled a list of the top 5 highest-ranked (based on the dot-voting) topics from each community, resulting in 23 topics due to overlap between communities. We then used the Qualtrics data collection platform to create an online survey that asked respondents to select the 5 topics on the compiled list that they felt were highest priority for PEACHnet to address. We emailed the survey to all participants from both rounds of meetings, as well as other contacts we had made through the course of our engagement activities. We again asked that participants share the survey with networks of friends or coworkers to

Table 1. Demographic Characteristics of Meeting and Survey Participants

\begin{tabular}{|c|c|c|c|}
\hline & $\begin{array}{l}\text { First Round of Meetings } \\
\qquad \begin{array}{c}\mathrm{N}=65) \\
\mathrm{n}(\%)\end{array}\end{array}$ & $\begin{array}{l}\text { Second Round of Meetings } \\
\qquad \begin{array}{c}\mathrm{N}=86) \\
\mathrm{n}(\%)\end{array}\end{array}$ & $\begin{array}{c}\text { Survey } \\
(\mathrm{N}=199) \\
\mathrm{n}(\%)\end{array}$ \\
\hline \multicolumn{4}{|l|}{ Race $^{*}$} \\
\hline White & $55(85)$ & $71(83)$ & $182(91)$ \\
\hline Latinx & $2(3)$ & $4(5)$ & $16(8)$ \\
\hline Native American/American Indian & $4(6)$ & $5(6)$ & $2(1)$ \\
\hline Asian & $3(5)$ & $1(1)$ & $1(0.5)$ \\
\hline Other & $1(2)$ & $2(2)$ & $2(1)$ \\
\hline Prefer Not To Say & $0(0)$ & $0(0)$ & $3(1.5)$ \\
\hline \multicolumn{4}{|l|}{ Sex and Gender } \\
\hline Female & $56(86)$ & $67(78)$ & $166(83)$ \\
\hline Male & $9(14)$ & $18(21)$ & $31(16)$ \\
\hline Non-binary/Third Gender & $0(0)$ & $1(1)$ & $1(0.5)$ \\
\hline Prefer Not To Say & $0(0)$ & $0(0)$ & $1(0.5)$ \\
\hline \multicolumn{4}{|l|}{ Age, years } \\
\hline 20 to 29 & $11(17)$ & $22(26)$ & $18(9)$ \\
\hline 30 to 39 & $12(18)$ & $20(23)$ & $45(23)$ \\
\hline 40 to 49 & $17(26)$ & $14(16)$ & $74(38)$ \\
\hline 50 to 59 & $8(12)$ & $14(16)$ & $32(16)$ \\
\hline $60+$ & $5(8)$ & $13(15)$ & $28(14)$ \\
\hline No response & $12(18)$ & $3(4)$ & $2(1)$ \\
\hline \multicolumn{4}{|l|}{ Stakeholder Group* } \\
\hline Medical Practice Staff & $9(14)$ & $13(15)$ & $23(12)$ \\
\hline Administrators & $12(18)$ & $9(14)$ & $52(26)$ \\
\hline Clinicians & $21(32)$ & $16(19)$ & $59(30)$ \\
\hline Public Health/CBO Staff & $12(18)$ & $11(13)$ & $50(26)$ \\
\hline Community Members $^{\dagger}$ & $11(17)$ & $37(43)$ & $41(21)$ \\
\hline Prefer not to say & $0(0)$ & $0(0)$ & $5(2.5)$ \\
\hline
\end{tabular}

Abbreviation: CBO, community-based organization.

${ }^{*}$ Sums to $>100 \%$ as multiple could be selected.

${ }^{\dagger}$ Community members who did not identify as part of any of the professional groups listed (most other stakeholders considered themselves community members as well). 
Figure 3. Examples of photographs submitted by second round meeting participants: A) a community garden supported by a primary care clinic; B) Empty buildings in a dwindling downtown area; C) Dilapidated housing; D) Open space described as beautiful but isolated; E) Bountiful garden produce; F) Image showing difficult parking situation in a community with no public transportation; G) A food pantry in a primary care practice; H) Screenshot demonstrating issues with health care access.
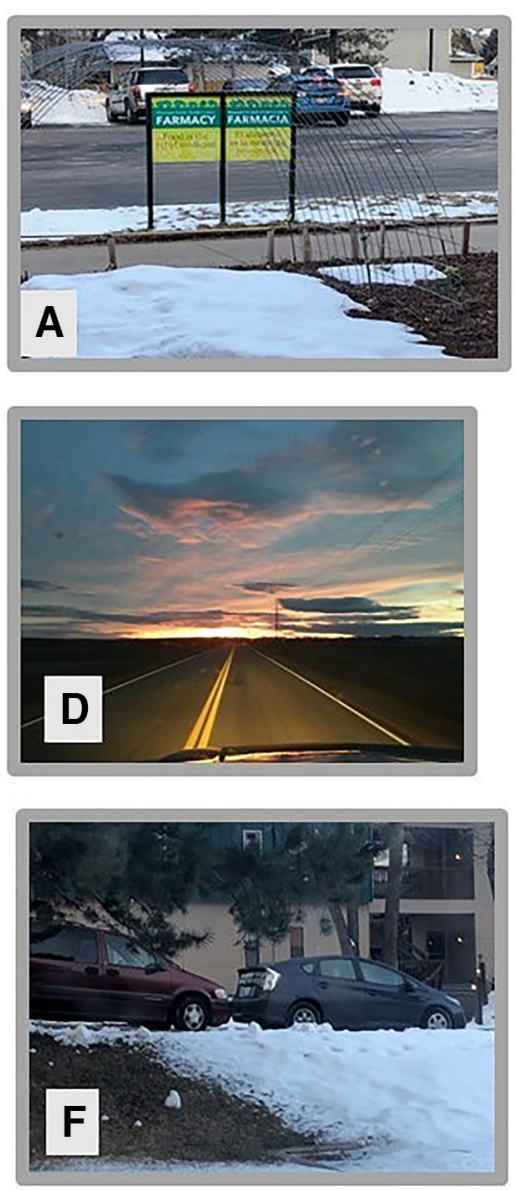
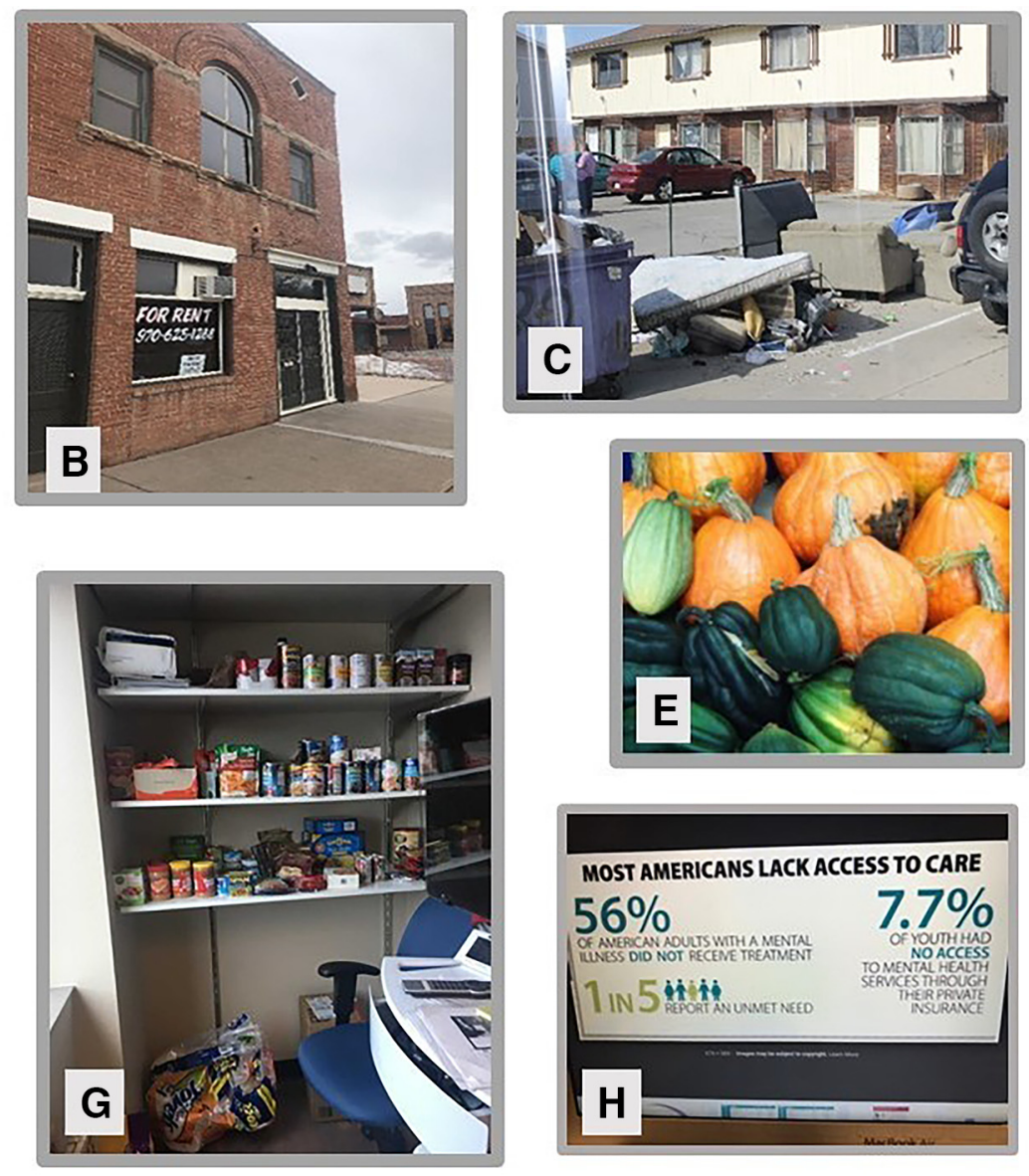

increase distribution. We analyzed survey data by calculating the selection frequencies for each topic listed, both overall and by stakeholder group.

\section{Results}

Meetings were held in 12 different communities across western Colorado, although 2 communities participated in only the first round of meetings and 2 in only the second round (see Figure 2). Sixty-five people attended the first round of meetings, with an attendance range of 1 to 9 participants. Eighty-six people attended the second round of meetings, with an attendance range of 3 to 14 . One hundred ninetynine people responded to the survey. Demographic characteristics of participants across all 3 phases are displayed in Table 1. Despite working through multiple channels, it was difficult to engage diverse populations, and most participants were white. For reference, western Colorado populations on average are $85 \%$ white, with Latinx populations being the largest minority group. In addition, the majority of participants were female, reflecting staff demographics and social networks at primary care practices, CBOs, and health departments.

Results of Photovoice: About half of all participants in the second round of meetings shared 1 or more images. This yielded a total of 84 images across all communities. There were 4 communities where meeting participants did not come with any images; we conducted NGT only in these communities. Of note, discussions in these communities resulted in similar topic elicitation. There were some common themes across the images that often 
Table 2. Topic Selection Frequency Across All Survey Respondents $(\mathbf{N}=199)$

\begin{tabular}{|c|c|c|}
\hline Rank & Topic & $\begin{array}{l}\text { Respondents Selecting Topic } \\
\mathrm{n}(\%)\end{array}$ \\
\hline 1 & Lack of access to mental and behavioral health services and high suicide incidence & $128(64)$ \\
\hline 2 & $\begin{array}{l}\text { Need for drug and alcohol abuse interventions and treatment options, as well as youth } \\
\text { prevention }\end{array}$ & $96(48)$ \\
\hline 3 & Lack of access to health care due to high cost of health services and insurance & $79(40)$ \\
\hline 4 & Lack of quality affordable housing & $63(32)$ \\
\hline 5 & Need for affordable and high-quality childcare & $58(29)$ \\
\hline 6 & Socioeconomic inequalities & $52(26)$ \\
\hline 7 & Chronic disease education, prevention, and self-management & $50(25)$ \\
\hline 8 & Adverse childhood experiences, traumatic life events, and PTSD & $47(24)$ \\
\hline 9 & Vaping, especially in kids & $45(23)$ \\
\hline 10 & $\begin{array}{l}\text { Health and wellness for senior populations, including connections to community and aging } \\
\text { in place }\end{array}$ & $40(20)$ \\
\hline 11 & Homelessness & $38(19)$ \\
\hline 12 & Loneliness and social isolation & $36(18)$ \\
\hline 13 & $\begin{array}{l}\text { Promoting and providing needed support and resources for an active lifestyle (ie, } \\
\text { recreational centers, transportation to outdoor opportunities) }\end{array}$ & $33(17)$ \\
\hline 14 & $\begin{array}{l}\text { Health challenges faced by immigrant and Latino populations (including access to service } \\
\text { in native language in culture) }\end{array}$ & $33(17)$ \\
\hline 15 & Lack of transportation & $33(17)$ \\
\hline 16 & Lack of access to and education about healthy and nutritious food & $28(14)$ \\
\hline 17 & Need for consumer education about insurance and healthcare costs & $28(14)$ \\
\hline 18 & Lack of clear information about healthcare costs & $27(14)$ \\
\hline 19 & Need for increased local access to emergency and specialty care & $33(12)$ \\
\hline 20 & Better access to community resources (such as social services organizations or food banks) & $22(11)$ \\
\hline 21 & Environmental health issues, including exposure to toxins & $9(5)$ \\
\hline 22 & Need for increased local options for childbirth & $8(4)$ \\
\hline 23 & Altitude-related hypoxia (low oxygen in blood) & $4(2)$ \\
\hline
\end{tabular}

Each Respondent Could Select up to Five Topics.

were related to positive and negative aspects of living in rural areas. For example, images captured how the isolation of rural living provided space for recreation and could be peaceful but could also limit social connection and access to resources. Other images included dilapidated housing, lack of transportation or food resources, and assets such as garden projects in the same communities (see Figure 3). During discussions of these images, the relationship between physical and mental health and the importance of social determinants of health frequently surfaced.

Results of Nominal Group Technique/Topicgenerating activities:

After organizing and grouping the topics that surfaced in the 11 meetings, the total number of topics for the survey was 23 as there was considerable overlap in topics across communities.

Table 2 presents the list of topics and frequency with which they were selected across all survey respondents. Figure 4 displays the percentage of respondents that selected the top 5 topics, both overall and disaggregated by respondent type. The lack of access to mental health care and high suicide incidence in the region was the most frequently selected topic overall and across all respondent types, indicating consensus around the need for research around mental health and suicide prevention in western Colorado. There were some differences by respondent groups in the frequency of selection of topics ranked second through fifth. For example, among staff from public health and community-based organizations, lack of quality affordable housing was the second most frequently selected topic while it was fifth among clinicians.

\section{Discussion}

Using strategies including multi-stakeholder meetings, Photovoice, and NGT, to engage potential 
Figure 4. Percentages of respondents selecting each of the top 5 most frequently selected topics, overall and by respondent type. Abbreviation: $\mathrm{CBO}$, community-based organization.

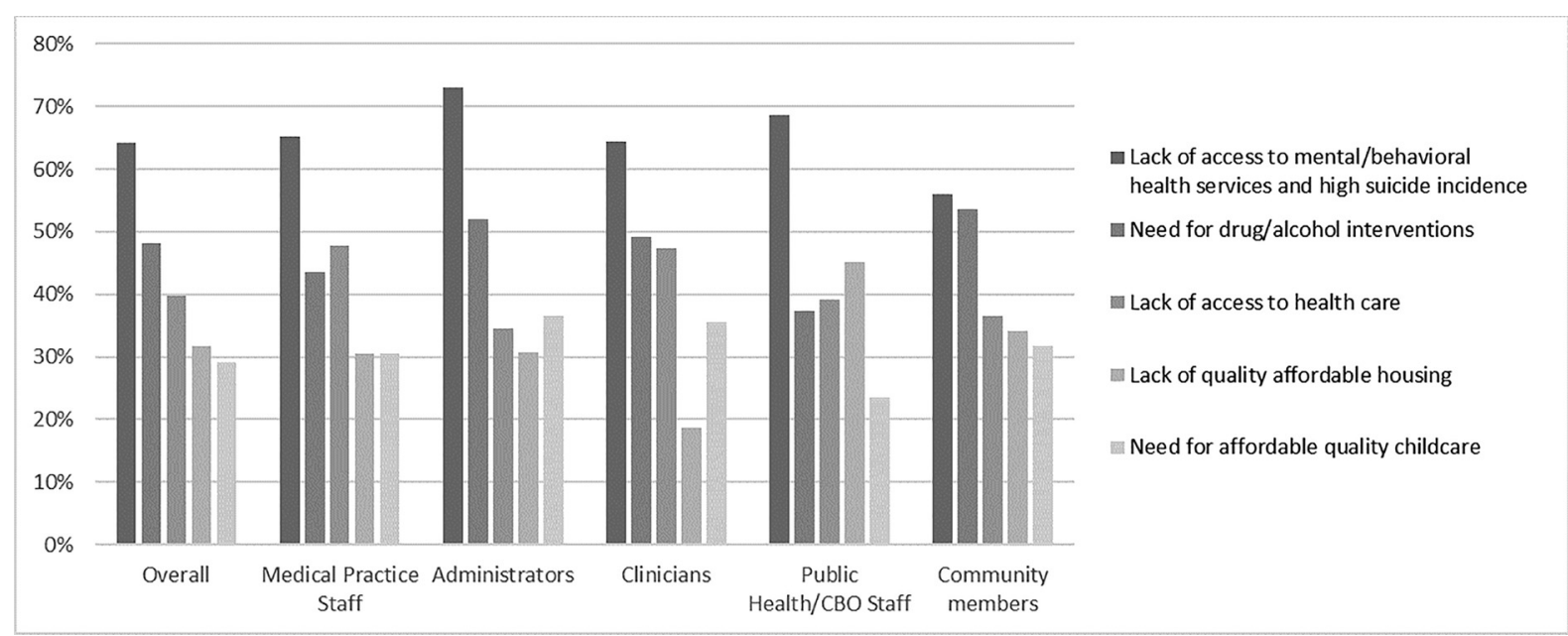

members of a developing PBRN allowed us to identify both interested partners and topics that could be explored with future research that was important to communities. We believe other investigators interested in conducting community-engaged research, whether as part of PBRN projects or not, could use a similar process to tap into their stakeholders' interests.

Interestingly, many of the topics we identified have historically been considered outside the wheelhouse of primary care and practice-based research and more in the realm of communitybased research. For example, while some of the Photovoice images portrayed specific medical issues, much of the discussion was around the intersection of health outcomes with mental health or needs related to the social determinants of health. This demonstrates community alignment with calls for primary care to adopt a population health focus and to collaborate with stakeholders such as public health departments. ${ }^{10}$ In 1 qualitative study involving PBRNs and public health departments, mutual awareness and developing a shared strategic vision were deemed crucial for increasing collaboration. ${ }^{19}$ Our work can be a step toward these goals by demonstrating that stakeholder groups in our region also believe this is an important and necessary part of improving health outcomes, both on a population and individual level Our findings also suggest that the stakeholders and partners we have engaged in this work are ready to move past traditional PBRN research, which has historically focused on clinical practice outcomes, and to now also participate in projects that involve community members and other organizations. Broadly, our findings suggest increasing overlap between practice-based and community-based research, as primary care practices increasingly integrate behavioral health services and undertake efforts to understand better and improve social determinants of health.

We are encouraged to have general agreement across the region and stakeholder groups as to the high-priority topics. We believe this is evidence that our engagement methods did tap into people's true concerns across the region. As further confirmation of this, several regional community health needs assessments, which aim to identify issues in communities that social service organizations and health care entities should address, have resulted in similar priority topics. ${ }^{20-23}$

Our findings also support our intention to develop a research network that includes stakeholders from multiple sectors. Our analysis of subgroup responses showed some minor differences that we can explore for future projects. For example, clinicians were less likely to choose a lack of affordable, quality housing as a priority than all other subgroups. We believe this variability demonstrates that involving various stakeholder types in prioritysetting captures differences in perspectives and may lead to research questions and projects with broader community support than projects reflecting only clinician input. Further support for this is found in evidence suggesting that research and interventions 
can be more effective when using communityengaged approaches. ${ }^{24}$

As is supported by results of other projects where Photovoice was used, we found that the use of Photovoice ensured that the voices of all meeting attendees were heard and provided an understanding of community need. ${ }^{25,26}$ While not everyone who attended meetings provided images, physicians were least likely to submit images, which we believe allowed other people to contribute in settings where often their voices are not heard. One potential limitation to our use of Photovoice is that topics not captured in the images may not have emerged in discussions, although many of the images elicited multiple topics - that is, the image of open space spurred discussion of the benefits of natural beauty and the challenge of living in an isolated community — and the NGT approach did not limit participants to topics captured by images.

Finally, our approach also allowed for rich discussion about the intersections of health-related challenges and identification of community strengths as well - something that does not always surface during research topic-generating activities. Identifying strengths when working in community engagement allows communities to understand and use solutions that are appropriate and practical in their own communities, which will be crucial to our success as a PBRN in western Colorado. ${ }^{16}$

\section{Future Directions}

The challenge that we now face is developing specific research questions and proposals from the list of priority topics we generated. Since these meetings were held, with input on the proposed focus from community stakeholders, we have submitted 2 proposals to PCORI for suicide prevention-related projects, receiving funding for 1 and awaiting review of another. The funded project involves convening stakeholders and partners from across western Colorado who are working in suicide prevention to share current work and identify gaps in evidence regarding best practices. This project will result in a specific research agenda for interventions related to suicide prevention in the near future. In addition, we are involved in several projects examining primary care practice screening and referral for needs pertaining to SDOH and are working across stakeholder groups to develop future related interventions. In our future work, we plan to guide stakeholders through a process to develop focused research questions around other priority topics to connect the results of our priority-setting process with tangible research efforts.

One limitation of our work was that the population that attended meetings and responded to the survey was primarily white and female. We believe this is due to the recruitment of participants through primary care practices and CBOs, where the staff tends to be female, and the fact that western Colorado is predominantly white. We recognize that we need to continue engagement efforts to reach underrepresented populations and are making a concerted effort in our continued work to connect with communities of color to ensure that our research represents all communities in western Colorado. For example, we have recently begun work with a county public health agency to engage with communities to address health literacy and equity in the Latinx population. For this project, our role is organizing a coalition of health care workers to listen to and learn from community members and strategize on how systems can adjust to address health equity. Meaningful engagement and involvement of western Colorado's Latinx community, and other underrepresented populations, continues to be an important goal for our future work.

We are grateful to everyone from western Colorado who has attended our PEACHnet meetings and shown interest in the development of this network and ongoing partnerships.

To see this article online, please go to: http://jabfm.org/content/ 35/1/115.full.

\section{References}

1. Agency for Healthcare Research and Quality. Primary Care Practice-Based Research Network. 2018. Available at: https://www.ahrq.gov/research/ findings/factsheets/primary/pbrn/index.html.

2. Davis MM, Keller S, DeVoe JE, Cohen DJ. Characteristics and lessons learned from practicebased research networks (PBRNs) in the United States. J Healthc Leadersh 2012;4:107-16.

3. Green LA, Hames CG, Nutting PA. Potential of practice-based research networks: experiences from ASPN. J Fam Pract 1994;38:400.

4. Westfall JM, Zittleman L, Staton EW, et al. Card studies for observational research in practice. Ann Fam Med 2011;9:63-68.

5. Green LA, Simmons RL, Reed FM, Warren PS, Morrison JD. A family medicine information system: The beginning of a network for practicing and resident family physicians. J Fam Pract 1978;7:567576. 
6. Hickner J, Green LA. Practice-based research networks (PBRNs) in the United States: growing and still going after all these years. J Am Board Fam Med 2015;28:541-545.

7. University of Colorado Anschutz Medical Campus. SNOCAP State Network of Ambulatory Practices and Partners. 2021. Available at: https://medschool. cuanschutz.edu/family-medicine/community/practicebased-research-networks/snocap.

8. Westfall JM, VanVorst RF, Main DS, Herbert C. Community-based participatory research in practice-based research networks. Ann Fam Med 2006;4:8-14.

9. Fisher M, Brewer SE, Westfall JM, et al. Strategies for developing and sustaining patient and community Advisory groups: lessons from the state networks of Colorado ambulatory practices and partners (SNOCAP) Consortium of practice-based research networks. J Am Board Fam Med 2019; 32:663-673.

10. Institute of Medicine Committee on Integrating Primary Care and Public Health. Primary care and public health: Exploring integration to improve population health. National Academies Press; 2012.

11. Israel BA, Schulz AJ, Parker EA, et al. Critical issues in developing and following CBPR principles. Community-based participatory research for health: Advancing social and health equity 2017;3: $32-35$.

12. Israel BA, Schulz AJ, Parker EP, Becker AB. Community-based participatory research: policy recommendations for promoting a partnership approach in health research. Education for Health: Change in Learning \& Practice 2001;14.

13. Colorado Health Institute. Colorado Regional Health Connectors. Available at: https://www. coloradohealthinstitute.org/research/colorado-regionalhealth-connectors.

14. Centers for Medicare and Medicaid Services. State Innovation Models Initiative: General Information.
2017. Available at: https://innovation.cms.gov/ innovation-models/state-innovations.

15. Catalani C, Minkler M. Photovoice: A review of the literature in health and public health. Health Educ Behav 2010;37:424-451.

16. Tremblay M, Baydala L, Littlechild R, Chiu E, Janzen T. Promoting the strengths and resilience of an Indigenous community through photovoice. Paediatr Child Health 2018;23:247-254.

17. Harvey N, Holmes CA. Nominal group technique: an effective method for obtaining group consensus. Int J Nurs Pract 2012;18:188-194.

18. Wang C, Burris MA. Photovoice: Concept, methodology, and use for participatory needs assessment. Health Educ Behav 1997;24:369-387.

19. Pratt R, Gyllstrom B, Gearin K, et al. Primary care and public health perspectives on integration at the local level: a multi-state study. J Am Board Fam Med 2017;30:601-607.

20. Mesa County Public Health. Mesa County Community Health Needs Assessment 2018-2020. 2018.

21. SJBPH Releases 2018 Community Health Assessment Data [press release]. 2019.

22. National Rural Health Resource Center. Valley View Hospital Garfield County, CO Community Health Needs Assessment. 2015.

23. UCHealth Yampa Valley Medical Center. Community Health Needs Assessment. 2019. 2019.

24. O'Mara-Eves A, Brunton G, Oliver S, Kavanagh J, Jamal F, Thomas J. The effectiveness of community engagement in public health interventions for disadvantaged groups: a meta-analysis. BMC public health 2015;15:1-23.

25. Newman SD, SCI Photovoice Participants. Evidencebased advocacy: Using photovoice to identify barriers and facilitators to community participation after spinal cord injury. Rehabil Nurs 2010;35:47-59.

26. Lal S, Jarus T, Suto MJ. A scoping review of the photovoice method: Implications for occupational therapy research. Can J Occup Ther 2012;79:181-190. 